\title{
Bacterial infections in lung transplantation
}

\author{
Margaret McCort ${ }^{1}$, Erica MacKenzie ${ }^{2}$, Kenneth Pursell ${ }^{2}$, David Pitrak ${ }^{2}$ \\ ${ }^{1}$ Albert Einstein College of Medicine, Division of Infectious Disease, New York, NY, USA; ${ }^{2}$ University of Chicago Medicine, Section of Infectious \\ Diseases and Global Health, Chicago, IL, USA \\ Contributions: (I) Conception and design: D Pitrak; (II) Administrative support: None; (III) Provision of study materials or patients: None; (IV) \\ Collection and assembly of data: All authors; (V) Data analysis and interpretation: None; (VI) Manuscript writing: All authors; (VII) Final approval of \\ manuscript: All authors. \\ Correspondence to: David Pitrak, MD. Professor of Medicine, Chief of Infectious Diseases and Global Health, Co-Director, Chicago Center for HIV \\ Elimination, University of Chicago, 5841 S. Maryland Ave., MC 5065, Chicago, IL 60637, USA. Email: dpitrak@medicine.bsd.uchicago.edu.
}

\begin{abstract}
Lung transplantation has lower survival rates compared to other than other solid organ transplants (SOT) due to higher rates of infection and rejection-related complications, and bacterial infections (BI) are the most frequent infectious complications. Excess morbidity and mortality are not only a direct consequence of these BI, but so are subsequent loss of allograft tolerance, rejection, and chronic lung allograft dysfunction due to bronchiolitis obliterans syndrome (BOS). A wide variety of pathogens can cause infections in lung transplant recipients (LTRs), including a number of nosocomial pathogens and other multidrug-resistant (MDR) pathogens. Although pneumonia and intrathoracic infections predominate, LTRs are at risk of a number of types of infections. Risk factors include altered anatomy and function of airways, impaired immunity, the microbial flora of the donor and recipient, underlying medical conditions, and genetic factors. Further work on immune monitoring has the potential to improve outcomes. The infecting agents can be derived from the donor lung, pre-existing recipient flora, or acquired from the environment over time. Certain infections may preclude lung transplantation, but this varies from center to center, and more recent studies suggest fewer patients should be disqualified. New molecular methods allow microbiome studies of the lung, gut, and other sites that may further our knowledge of how airway colonization can result in infection and allograft loss. Surveillance, early diagnosis, and aggressive antimicrobial therapy of BI is critical in LTRs. Antibiotic resistance is a major barrier to successful management of these infections. The availability of new agents for MDR Gram-negatives may improve outcomes. Other new therapies, such as bacteriophage therapy, show promise for the future. Finally, it is important to prevent infections through peri-transplant prophylaxis, vaccination, and infection control measures.
\end{abstract}

Keywords: Bacterial infections (BI); lung transplantation

Submitted Jun 23, 2020. Accepted for publication Feb 18, 2021.

doi: $10.21037 /$ jtd-2021-12

View this article at: http://dx.doi.org/10.21037/jtd-2021-12

\section{Introduction}

Lung transplantation has lower survival rates compared to other solid organ transplants (SOT) as a result of higher rates of infections and rejection (1-4). Infectious complications cause significant morbidity and mortality at all time points post-transplantation and the cause of death in a majority of lung transplant recipients (LTRs) (5). Bacterial infections (BIs) are the most frequent infectious complications. Despite modern approaches to immunosuppression and antimicrobial prophylaxis, opportunistic pathogens can still cause infection, but BIs predominate, most frequently in the first year for all SOT, including lung transplants (3). In the Swiss Transplant Cohort Study, 55\% of all LTRs developed infections in the first year, and $63 \%$ of these infections were bacterial (5). Another study reported $69 \%$ of LTRs were diagnosed with BIs, most often with Gram-negative isolates (6). There was 
reduced survival with $A$. baumannii infections, and overall $43 \%$ developed bronchiolitis obliterans syndrome (BOS). Overall 50-85\% of LTRs have at least one episode of BI (7). Most BIs occur in the early post-transplant period and upwards of $80 \%$ affect the lung, mediastinum, and pleural space $(2,5)$. While BIs are common, they have lower mortality compared to viral or fungal infections $(8,9)$. In absolute numbers, however, bacterial pneumonias are responsible for most of early infectious deaths $(10,11)$. Other serious life-threatening BIs also occur. BIs are a problem for pediatric LTRs as well as adult LTRs (12).

Infections also play a role in rejection and chronic allograft dysfunction (13). Chronic rejection characterized as obliterative bronchiolitis on pathological examination is a major barrier to lung allograft survival. Infections increase the risk of BOS, and BOS is subsequently the major predisposing factor for increased risk of infections (14). Each class of infection (bacterial, viral, and fungal) has been associated with chronic allograft dysfunction (15).

\section{Risk factors}

The risk of BIs is the sum of exposures to infectious agents and effects of immunosuppression on host defense to these agents. LTRs are at risk for infection with common nosocomial pathogens, as well organisms with which they colonized or infected pre-transplant. Twenty-three percent of LTRs with deep surgical site infections were infected with organisms colonizing the patient's native lungs pretransplant (16). In particular, cystic fibrosis (CF) patients are frequently affected by infections with MDR organisms pre-transplant, and this leads to $r$ recurrent infections with these organisms and poor outcomes.

\section{Time after transplant}

Similar to other SOT, the risk of infection, including BIs, following lung transplantation varies according to time from transplant $(17,18)$. The vast majority of infections occur in the first year following transplant, with most BIs occurring in the first 3 months post-transplant (19). Pneumonia is common, but deep surgical site infections, empyema, wound infections, mediastinitis, sternal osteomyelitis, and pericarditis also occur, and are associated with decreased survival at 1 year $(19,20)$.

Risk factors for late infections in different SOT, occurring $>6$ months post-transplant, include acute rejection occurring in the early post-transplant period, relapsing
CMV infection, and previous BIs (21). Lung transplantation itself is a risk factor compared to other SOT.

\section{Etiologic agents}

In the first month post-transplant, infections with hospitalacquired multidrug-resistant (MDR) pathogens such as vancomycin-resistant Enterococcus (VRE), methicillin resistant Stapbylococcus aureus (MRSA), and MDR Pseudomonas aeruginosa (PsAR) and other gram-negative rods (GNRs) predominate (22-27). There are a number of sources of these infections, including both donor and recipient lungs, central and peripheral intravenous catheters, arterial catheters, urinary catheters, wounds, and leaks at the anastomoses. Corynebacterium spp. have been associated with infections of the anastomosis and stents (28). Mycoplasma hominis can cause intra-thoracic infections (29,30). Clostridium difficile infection (CDI) is also a frequent complication $(31,32)$. Some LTRs have a particularly difficult time with pathogens unique to their underlying pulmonary disease, for example, pneumonia with Burkholderia spp. in CF patients (33).

Between one and six months post-transplant, anastomotic leaks and CDI continue to be prevalent. Moat patients in this period receive routine Pneumocystis jirovecii pneumonia (PCP) prophylaxis with trimethoprim-sulfamethoxazole (TMP/SMX), which may also prevent BIs. Despite this, breakthrough infections with Nocardia are occasionally seen. Mycobacterium tuberculosis (MTB) and other mycobacterial may arise.

Greater than six months post-transplant, common community-acquired pathogens causing pneumonia and urinary tract infections (UTIs) are encountered. Strep. pneumoniae becomes a significant pathogen. Nocardia spp. and Rhodococcus equi infections have also been reported.

\section{Pathogenesis}

The factors leading to BIs after lung transplantation include anatomic abnormalities, potent immunosuppression, the recipient's own colonizing flora, the flora of the donor and the allograft, and changes in flora post-transplant with constant exposure to the environment, as well the patient's own genetic makeup.

\section{Anatomic factors}

LTRs have altered anatomy that predisposes them to 
infection, most specific for pneumonia. There is impaired cough reflex, decreased mucociliary clearance, disruption of $f$ bronchial circulation lymphatic drainage, all of which contribute to risk of pneumonia $(34,35)$. Bronchial stenosis is associated with higher rates of tracheobronchitis, pneumonia, and more inpatient days (36).

\section{Immune factors}

Lung transplantation has been described as "an immune state characterized by an increase in infections and an alloreactive state" (37). Intensification of immunosuppression to manage rejection and BOS dramatically raises the risk of infection.

Immune suppression reduces Th1 cytokines and decreases macrophage function, impairing host defense against BIs. Patients who have infections have decreased T cell intracellular cytokine production by cells collected by BAL compared to patients without infection (38).

Investigators have studied measures of immunosuppression to determine infection risk (39). The Cylex ImmuKnow assay assesses the function of lymphocytes by measuring production of ATP in response to mitogen stimulation. In 175 LTRs who had 129 infectious episodes, the ATP values for patients developing CMV disease or BIs were significantly lower compared to stable patients (40).

Humoral immune defects also occur, even if patients have not received induction therapy or anti-rejection therapy targeting B cells. Goldfarb reported that $70 \%$ of LTRs developed hypogammaglobulinemia (HGG), and in $37 \%$ it was severe (IgG $<400 \mathrm{mg} / \mathrm{dL})$ (41). Severe HGG was associated with an increased risk for bacterial and fungal infections and increased mortality. Pediatric LTRs also develop significant HGG associated with increased risk of infection and length of hospital stay (42). HGG is not unique to lung transplantation, occurring with other SOT, with severe HGG occurring in 15\% (43). A meta-analysis of HGG in SOT calculated a 21.9 times higher relative risk of death for patients with severe HGG in the first year posttransplant (44). Some authorities have recommended routine monitoring for HGG in SOT and replacement therapy when appropriate (45). Other measures of humoral immunity ( $\mathrm{IgG}$ subsets, IgA, complement levels, pathogen-specific titers, etc.) may also predict BIs $(46,47)$. Pre-transplant levels of IgG and IgA may also be predictive $(48,49)$. Despite the potential benefit of assessing immune markers to determine the risk for BIs, there is no test or set of tests that are currently recognized as a standard of care (50).

\section{Microbial flora}

The microbiome of LTRs plays an important role in the pathogenesis of BIs. Although donor graft, blood, and preservation fluids may be infected with MDR bacteria, these usually do not cause infection in the recipient if appropriate prophylaxis directed against the donor isolates (51). The recipient's pre-transplant flora is very important. Patients with high bacterial burden, i.e., those with CF and bronchiectasis, are especially problematic $(52,53)$. Antibiotic resistance due to previous antibiotic exposure contributes to poor outcomes (23-28,52,54). Even though native lungs are removed, rapid colonization of the allograft with pre-transplant strains occurs, perhaps from a focus in the sinuses (55-57). Infections with certain pathogens, including PsAR, Stenotrophomonas, Burkbolderia spp., and mycobacteria adversely affect outcomes in LTRs and are carefully considered during recipient selection. Colonization or infection with MDR bacteria may be a contraindication to lung transplantation (58). Infection with $B$. cepacia was often associated with poor outcomes and considered a contraindication to transplantation (59). B. cepacia, however, is actually a complex of several distinct species. Certain species of the Burkholderia cepacia complex, such as B. gladioli and B. cenocepacia, contribute more to poor outcomes than other species (60). The data on the effects of existing microbial flora on outcomes has varied from study to study. Several studies have shown the presence of MDR bacteria does not necessarily increase the risk of infection or death $(61,62)$. Each center needs to decide if colonization or infection with MDR-GNRs precludes lung transplantation $(63,64)$. Non-tuberculous mycobacterial infections may also have excess morbidity and mortality, but again, these infections may not be a contraindication to transplantation (65-71).

\section{Microbiome}

New molecular methods have allowed characterization of the microbiome of respiratory tract, gut, and other sites. SOT and stem cell recipients all have changes in the gut microbiome, a consequence of antibiotic therapy (72). The gut microbiome can significantly affects pulmonary health in CF. The microbiome of the lower respiratory tract in patients with chronic pulmonary disease, such as CF, is complex (73). LTRs have a unique microbiome that is different from pre-transplant, and there are further changes over time $(57,74,75)$. Studies are underway to 
understand the relationship between the microbiome and post-transplant infections, rejection, and chronic allograft dysfunction.

\section{Genetics}

Genetic studies also have the potential of providing insights into the pathogenesis of BIs in LTRs Polymorphisms in TLR4 that mediate endotoxin hypo-responsiveness were associated with a significantly lower risk of rejection in the first 3 years in LTRs, with a trend toward decreased risk of BOS (76). Innate immune signaling is a potential therapeutic target for preventing allograft rejection. Genetic studies in heart transplant patients may also be pertinent to the risk of infections in LTRs. Late BIs were associated with polymorphisms of HMOX1, a gene regulating neutrophil activation, while viral infections were associated with polymorphisms of CTLA4, a regulator of $\mathrm{T}$ cell activation (77). Stem cell transplant recipients with a genetic deficiency of pentraxin 3 (PTX3), a soluble pattern recognition receptor that is important in innate immunity, have increased risk of invasive aspergillosis due to reduced antifungal capacity of neutrophils (78). In CF, it is known that colonization with PsAR is associated with reduced levels of PTX3 in airway sections $(79,80)$. Future studies will likely uncover other genetic predispositions to BIs in LTRs.

\section{Other recipient related factors}

LTRs with renal failure, morbid obesity, or malnutrition are at increased risk of infection. Preceding viral infections, especially influenza A, can lead to bacterial superinfection (81). Mechanical ventilation and ECMO pre-transplant are associated with higher mortality, possibly related to a higher risk of BIs, but may not be a contraindication $(82,83)$. Recipients treated with corticosteroids or antibiotics prior to transplantation have a higher incidence of BIs. Finally, lung transplantation for HIV-infected patients might be expected to have a greater risk of infection due to impaired immunity. The data is limited compared to kidney and liver transplants, but it seems HIV-infected LTRs have similar survival rates LTRs without HIV (84).

\section{Effects of bacterial infections on lung allografts}

Infections can adversely affect graft function, increasing the risk of rejection and $\mathrm{BOS}(7,8,15,85-87)$. Activation of the innate immune system can potentiate adaptive immunity and induce lung rejection (88). Microbes stimulate chemokine production and recruitment of leukocytes to the transplanted lung (15). Those leukocytes further upregulate chemokine release and recruitment of mononuclear cells that can initiate an alloresponse. Rat models of lung transplantation have shown that CMV and Listeria infections enhance chronic rejection (89). Animal studies show BIs can induce production of G-CSF, subsequent neutrophilia and graft infiltration, inducing acute rejection. Neutrophil elastase activity is increased with BI, and this may contribute to lung allograft damage (90).

Colonization with Gram-negative bacteria, in particular PsAR, can increase the risk of BOS (91-93). Interestingly, recolonization with previous Gram-negative flora in LTRs with CF was protective against chronic allograft dysfunction, while de-novo colonization with new Gramnegative species is a risk factor for this complication (94). Studies have suggested a connection between PsAR colonization and gastroesophageal reflux disease (95). Yamamoto and colleagues demonstrated that PsAR infection can stimulate B7 expression on neutrophils infiltrating the lung, resulting in CD4+ $\mathrm{T}$ cell activation and abolishing graft tolerance (96). They also showed it is possible to block B7 and still clear PsAR, a potential therapeutic strategy. Increased endothelin-1 is associated with bacterial lung infection, resulting in increased fibrosis, a major part of the pathogenesis of bronchiolitis obliterans (97). CDI has also been associated with BOS, presumably due to systemic inflammation $(31,98)$.

\section{Diagnosis}

Prompt diagnosis of BI and initiation of therapy is critical. The diagnostic evaluation depends on the suspected site(s) of infection. Collection of blood, urine, and sputum specimens for smears and cultures as soon as possible in infectious work-up is very important, as these are the usual sources of infection. Urinary antigen testing can identify pneumonia due to Strep.pneumoniae and Legionella pneumophila. In the case of Legionella, however, urinary testing can be used only for diagnosis of L. pneumophila serotype 1. Infection with other serotypes or other species (e.g., Legionella micdadei) requires culture, typically from BAL fluid. Bronchoscopy is safe and helpful for the etiologic diagnosis of pneumonia, with results of microbiological samples collected leading to modification of antimicrobial therapy in $35 \%$ of cases (99). In LTRs, 
there is a non-specific increase in procalcitonin (PCT) postoperatively, followed by a progressive decline during the first week post-transplant. After that an increase in PCT is significantly associated with BI (100). The use of any biomarker, however, is still not standard of care.

\section{Site specific infections}

BIs account for more than half of the infections after lung transplantation, and similar to other SOT, the allograft is most common site of BI (5). LTRs, however, also experience a high incidence of $\mathrm{BI}$ at other sites.

\section{Early-onset pneumonia}

Bacterial pneumonia is the most common infection in LTRs, and occurs most frequently during the first month posttransplant $(1,7,101,102)$. LTRs are particularly susceptible to pneumonia because of impaired post-operative function of the lung allograft, impaired mucociliary clearance, and denervation, which interferes with the cough reflex. The lung allograft is the only transplanted organ that is directly exposed to the environment. LTRs are at increased risk for early pneumonia from MDR Gram-positive bacteria (such as MRSA) or GNRs (Enterobacteriaceae, PsAR), especially during prolonged exposure to the healthcare setting $(1,5,19,101-105)$. PsAR is the causative organism most often isolated (33\%), followed by Staph. aureus (26\%) and Acinetobacter (16\%) (101). Another large retrospective study found that 178 of 208 LTRs experienced a total of 859 infections (106). Most were respiratory tract (65.1\%), followed by mucocutaneous (oral mucosa, skin, and wound; $10.2 \%)$, and bloodstream infection (BSI) (9.9\%). The majority of respiratory infections were bacterial (83.6\%), most frequently due to GNRs with PsAR being the single most commonly isolated pathogen. Early post-transplant bacterial colonization and pneumonia may also be related to aspiration events, and gastroparesis plays a role as well (107).

\section{Late pneumonia}

Bacterial pneumonias continue to be a significant complication in LTRs, even after 6 months post-transplant. Though traditional risk stratification for post-transplant infection implicated nosocomial pathogens early and opportunistic pathogens later in the post-transplant course, the evolution of immunosuppression regimens and routine antimicrobial prophylaxis has led ongoing risk of non- opportunistic BIs occurring at any time in the first year after LT. Delayed onset bacterial pneumonia in LTRs is largely driven by patient exposures and residual immune deficits (108). Patients are still exposed to the healthcare environment, and allowing ongoing risk of acquiring nosocomial pathogens $(5,108,109)$. In one study PsAR was responsible for $54 \%$ of respiratory infections occurring after 1 year (106). Community-acquired pathogens (such as Streptococcus pneumoniae and Legionella), however, may become more frequent than nosocomial pathogens in delayed post-transplant pneumonia as immunosuppression is decreased and patients are less frequently exposed to the hospital (110-114). One retrospective analysis noted an incidence of invasive pneumococcal infection in LTRs of 22.7 per 1,000 patient-years, with a median time of diagnosis of 1.3 years post-transplant (111). Interestingly, all the patients with pneumococcal infections were receiving TMP/SMX, and the isolates obtained were resistant to this agent in $71 \%$ of cases. The diagnosis of Legionella infection may be difficult and should be considered in patients with progressive pneumonia despite broad-spectrum antibiotic therapy (112-114). Legionella infection can be nosocomial or community acquired. LTRs with legionellosis may develop empyema or non-pulmonary infections $(8,112)$.

Bacterial pneumonia as a consequence of viral respiratory tract infection is another important infectious risk in LTRs. Influenza, parainfluenza, and respiratory syncytial virus are all commonly isolated viral pathogens, particularly pneumonia occurring in the past post-transplant period $(1,80,106)$. Secondary bacterial pneumonia contributes significantly to morbidity and mortality associated with influenza infection, responsible for up to $25 \%$ of influenza deaths (115-118). The typical superinfecting pathogens are Staph. aureus, Strep. pneumoniae, and Haemophilus influenzae.

\section{Donor-derived BIs}

Donor-derived infections may manifest during the first few weeks after lung transplant. BIs derived from deceased donors may include nosocomial MDR pathogens resistant to routine surgical prophylaxis, such as MRSA, VRE, or MDR GNRs $(103,119,120)$. Culture data on bacteria present in the donor allograft and recipient lungs prior to transplant can be helpful in targeting post-transplant antimicrobial prophylaxis (100). One study found that $21 \%$ of BIs in LTRs were due to bacteria colonizing the donor lung, compared to $40 \%$ of BIs due to bacteria colonizing the recipient pre-transplant (106). Other studies have shown donor lung colonization does not 
change the incidence of pneumonia post-transplant, and outcomes may not be different if donor-derived bacteria are not appropriately covered by the prophylactic antibiotics administered (121-123).

\section{BIs in CF}

Patients with CF are at increased risk for both early and delayed bacterial pneumonia after lung transplantation due to underlying bacterial colonization with MDR pathogens, as well as ongoing dysfunction of native sinus tracts and upper airways $(33,52,56,57,62-64,124)$. Many studies have shown that CF patients are more likely to have positive pretransplant sputum or BAL cultures and are at increased risk for post-transplant pneumonia from these colonizing organisms. The data on outcomes with pre-transplant colonization are variable, and it is not clear that mortality is higher $(54,59-64,124,125)$. CF patients may also be at increased risk for BSI or SSTI after lung transplant, though most case series are limited by small numbers patients in single-center cohorts $(16,126)$.

\section{Tracheobronchitis}

Bacterial tracheobronchitis occurs when airways with prior mucosal damage develop infection, most frequently from pathogens colonizing the upper respiratory tract, and thus occurs most frequently in the first 3 months after lung transplantation. In LTRs the anastomosis of native upper airways with donor bronchi is particularly prone to infection, especially when the anastomosis is poorly vascularized or bronchial stenosis is present $(36,108)$. Diagnosis of tracheobronchitis is typically made by bronchoscopy revealing purulence, ulceration, necrosis, or dehiscence. Tracheobronchitis occurred before bacterial pneumonia in $90 \%$ of cases in one cohort study (105). Gastroparesis and aspiration increase the risk for both tracheobronchitis and pneumonia in mechanically ventilated patients, and ventilator-associated tracheobronchitis has been associated with longer duration of ventilation and length of stay $(107,127)$.

\section{Eтруета}

Infections of the pleural space early after LT are often precipitated by accumulation of fluid after removal of post-surgical chest tubes, either related to pneumonia or hemorrhage. Empyema has been reported in 3-5\% of LTRs, often occurring during the first 2 weeks posttransplant $(20,128,129)$. Although uncommon, it is particularly important to identify pleural space infection in LTRs as this is associated with increased mortality. In a study of 392 LTRs, the incidence of empyema did not differ between type of lung transplant (unilateral or bilateral) or among indications for transplant (128). The investigators did note that prophylactic antibiotics may have lowered the expected rate of empyema among the few CF patients in this study.

\section{Mediastinitis and sternal osteomyelitis}

Mediastinitis after sternotomy is associated with high morbidity and mortality, especially after heart and lung transplantation. The incidence of mediastinitis after cardiothoracic surgery is usually reported to be $1 \%$, but there is a higher risk associated with ECMO, cardiac assist devices, or organ transplantation (16,130-132). In one single center study, $16 \%$ of patients at a single center developed mediastinitis post-transplant (16). Although S. aureus has been identified as the most common causative organism in cardiac transplant-associated mediastinitis, numerous other pathogens (including PsAR, Staph. epidermidis, Escherichia coli, and Klebsiella pneumoniae) have been implicated in mediastinitis occurring in LTRs (130). Sternal osteomyelitis is also on the spectrum of deep surgical site infections and has been reported in 6\% of LTRs (16). Surgical approach, presence of hardware, and sternal vascularization may increase the risk of sternal osteomyelitis. Surgical debridement for mediastinitis and sternal osteomyelitis has been associated with better outcomes than antibiotic therapy alone.

\section{Blood stream infections}

BSIs have been reported to occur in $11.5 \%$ of LTRs (133). While the lungs are an important source of BSI, especially in the early post-transplant period, vascular catheters and CF have also been found to increase the risk for BSI. BSI in LTRs have been independently associated with increased mortality, up to $25 \%(106,126,133,134)$.

\section{Other BIs}

LTRs are also at risk for other BIs, including urinary tract infections (UTIs), skin and soft tissue infection (SSTI), and diarrhea from CDI. UTI has been reported in 3.1\% 
of LTRs in one study, with PsAR being most frequently implicated (106). SSTIs may be seen in the early posttransplant period. One study found that $29 \%$ of LT recipients experienced soft tissue surgical site infection (36). The risk of SSTI is supported by more recent guidelines on surgical site infections (SSI) in LTRs (135). ECMO may increase the risk for SSI infection in LTRs (136). SSTI occurring later in the post-transplant period may be related to poor wound healing associated with certain immunosuppressive agents.

SOT recipients are at increased risk for CDI due to prolonged hospital exposure, immunosuppressive use, and antibiotic prophylaxis $(31,32,98)$. CDI incidence in LTRs has been estimated between 7-33\% (137). In the Swiss Transplant Cohort Study, LTRs had higher incidence of CDI compared to all other SOT recipients (31). CDI after lung transplantation has been associated with increased risk of graft loss, as well as being an independent risk factor for mortality.

\section{Atypical pathogens}

Mycobacterial infection after lung transplantation is relatively uncommon, but the risk of infection with MTB and non-tuberculous mycobacteria (NTM) is greater than the general population $(65-71,103,138)$. SOT recipients have increased incidence of MTB infection, and in general LTR are at greater risk (139-144). In countries where MTB disease is endemic, disease most often occurs from reactivation of latent TB infection (LTBI). MTB can also be derived from the donor (145).

Several NTM have been reported to cause infection, but M. abscessus has been particularly problematic (65-71,146-149). Doucette et al. reported a case of a LTR with M. abscessus of the sternum requiring extensive debridement (146). Recipient cultures were positive for $M$. abscessus prior to the transplant. M. abscessus is observed in LTRs at an increased incidence compared to other SOT. In LTRs, it may cause SSTIs, pneumonia, and even disseminated disease. The most common presentation in all SOT recipients is cutaneous disease. These infections are reported throughout the post-transplant period without a partiality to a specific time period. Pleuropulmonary disease is most commonly described in LTRs. There is an increase in both mortality and disseminated disease associated with $M$. abscessus in SOT recipients. Mycobacterium avium complex and other NTM infections occur less frequently, and in general these infections are less severe compared with $M$. abscessus infection. If clinical, microbiological, and radiographic evidence is concerning for NTM infection pre-transplant, this must be addressed by further evaluation and treatment prior transplantation.

Nocardia spp., partially acid-fast organisms, are encountered less frequently, but infection is associated with increased in mortality in LTR $(150,151)$. Husain and coworkers reported that Nocardia infections were diagnosed in $0.6 \%$ to $2.1 \%$ of LTRs, but these patients had a mortality rate $40 \%$, attributed to Nocardia in $75 \%$ of the deaths (150). LTR who had Nocardia infections typically had nonspecific findings on imaging and the tendency for native lung involvement in single LTR. The authors hypothesized that this was the result of structural and functional abnormalities of the native lung versus reactivation of pre-existing infection. LTR receiving TMP/SMX prophylaxis were among those who developed Nocardia infection, highlighting that TMP/SMX resistant strains exist and prophylaxis should not preclude Nocardia as a potential pathogen in LTRs. Cutaneous disease are the most common form of extra-pulmonary disease and skin lesions have been reported in liver and renal transplant recipients, but in the Hussain study they did not find any cutaneous lesions in their LTRs or reports from other cases they reviewed. Nocardia should always be considered as a potential pathogen in LTRs with progressive disease despite appropriate antibiotic therapy. Rhodococcus equi, another partially acid-fast organism, has also been reported in SOT, including LTR (152).

Mycoplasma bominis may cause infection in LTRs $(29,30)$. Another infection, which may be donor-derived, with unusual consequences is infection with Ureaplasma urealyticum or Ureaplasma paroum (153-156). Donors with this organism have been young, presumably sexually active, and often had a documented aspiration event prior to death (152). Infection is characterized by lung infiltrates and sepsis, but also a potentially lethal hyperammonemia syndrome with mental status changes and cerebral edema. The hyperammonemia can be prevented or treated with antibiotic therapy, ideally azithromycin with doxycycline or a fluoroquinolone. These atypical pathogens do not grow on routine media, so special cultures or PCR are required for diagnosis.

\section{Therapy}

Therapy of post-transplant BI depends on the time after transplant and results of microbiologic studies. Early removal of infected or potentially infected central venous 
catheters, arterial catheters, and urinary catheters is important. In the first month after transplant, nosocomial pathogens predominate, and empiric therapy should have broad-spectrum coverage. Interestingly, MDR pathogens such as Acinetobacter baumannii, which are classically seen in the early post-transplant period are now increasingly being seen late ( $>6$ months) in the post-transplant course (157).

Overall rates of infections in LTRs have decreased, but now more infections in SOT involve MDR bacteria, particularly GNRs with extensive resistance (58,158-160). Mortality is higher in thoracic transplant recipients infected with nosocomial pathogens. LTRs may require extended ventilator support and significant exposure to broad-spectrum antibiotics, resulting in extensive drugresistant GNR infections and CDI. One study of LTRs that excluded patients with CF or survival $<30$ days looked at the development of $C$. difficile and/or a MDR infection (161). MDR infections occurred in $34 \%$ and CDI in 6\%. ICU days and duration of receiving Gram-positive antimicrobials were associated with an increased risk. Infections with carbapenem-resistant GNRs have been associated with decrease in allograft and patient survival (158).

\section{Choice of antibiotic(s)}

Directed anti-microbial therapy depends on the pathogen causing disease and the pattern of antimicrobial resistance. The emergence of multi-drug resistant (MDR) pathogens makes this choice particularly difficult, and therapeutic decisions should be based on the results of susceptibility testing $(160,161)$. MRSA can be treated with vancomycin, linezolid, or daptomycin, although daptomycin should be avoided in pneumonia due to MRSA. Vancomycinresistant Enterococci (VRE) can be treated with daptomycin or linezolid. GNRs producing AmpC $\beta$-lactamases can be treated with cefepime, but those producing extended spectrum $\beta$-lactamases (ESBLs) must be treated with carbapenems. Unfortunately, carbapenem-resistant Enterobacteriaceae (CRE) and carbapenem-resistant PsAR have emerged. Acinetobacter baumannii isolates can be extremely drug-resistant, often to most antibiotics. Some of the options for treatment of infections with this pathogen are high-dose ampicillin-sulbactam (with the beta-lactamase inhibitor having the antibacterial effect), carbapenems, or colistin. Colistin has also been used for MDR PsAR infections in LTRs (162). Unfortunately colistin has poor pulmonary penetration when given intravenously, and adjunctive therapy with inhaled colistin is frequently used.
A number of new drugs have been developed for MDR Gram negative pathogens, including ampC betalactamase and ESBL producing Enterobacteriaceae, CRE, carbapenem-resistant PsAR, and extensively drug-resistant (XDR) Acinetobacter $(163,164)$. Delafloxacin has been shown to be active against ampC and ESBL producing Enterobacteriaceae. Eravacycline has shown potent broadspectrum activity against a wide variety of microorganisms, including ESBL-producing Enterobacteriaceae and Acinetobacter. Drugs that have been approved for treatment of certain CRE infections include ceftazidime-avibactam, meropenem-vaborbactam, cefiderocol, and plazomicin. Ceftazidime-avibactam has been used successfully to treat a LTR with CF who developed Bulkholderia multivorans bacteremia and brain abscess (165). It is important that labs have the capability to perform susceptibility testing with established phenotypic tests or multiplex PCR methods for detection of the various $\beta$-lactamases. There are some published society recommendations on the management of MDR GNRs in SOT, including lung transplantation (166). Table 1 lists increasingly prevalent MDR pathogens and reasonable empirical anti-microbial coverage or alternative agents to test for susceptibility.

Less common pathogens include Nocardia, Listeria, and Rhodococcus. For Nocardia, treatment with TMP/SMX is generally the first line therapy, although given that many patients are on TMP/SMX develop breakthrough infections, alternative and even therapy (often with carbapenems, cephalosporins, or fluoroquinolones) should be considered $(150,151)$. Listeria is occasionally an opportunistic pathogen after SOT, and ampicillin is the drug of choice for this infection (167). Treatment of Rhodococcus equi may require administration of multiple agents, guided by the results of susceptibility testing (168). There are guidelines for management of MTB and NTM infections that also pertain to lung transplantation $(169,170)$. Therapy usually consists of multiple anti-mycobacterial drugs, and should be guided by susceptibility data and in consultation with ID specialists. Unfortunately rifamycins, which are frequently a component of theses regiments interact with multiple immunosuppressive agents.

\section{Future options}

Another promising approach to treatment of MDR organisms is bacteriophage therapy, and this has already been explored in LTRs with difficult to treat infections. Aslam and co-workers treated 3 LTRs with MDR 
Table 1 Therapeutic options for drug-resistant and multi-drug resistant pathogens

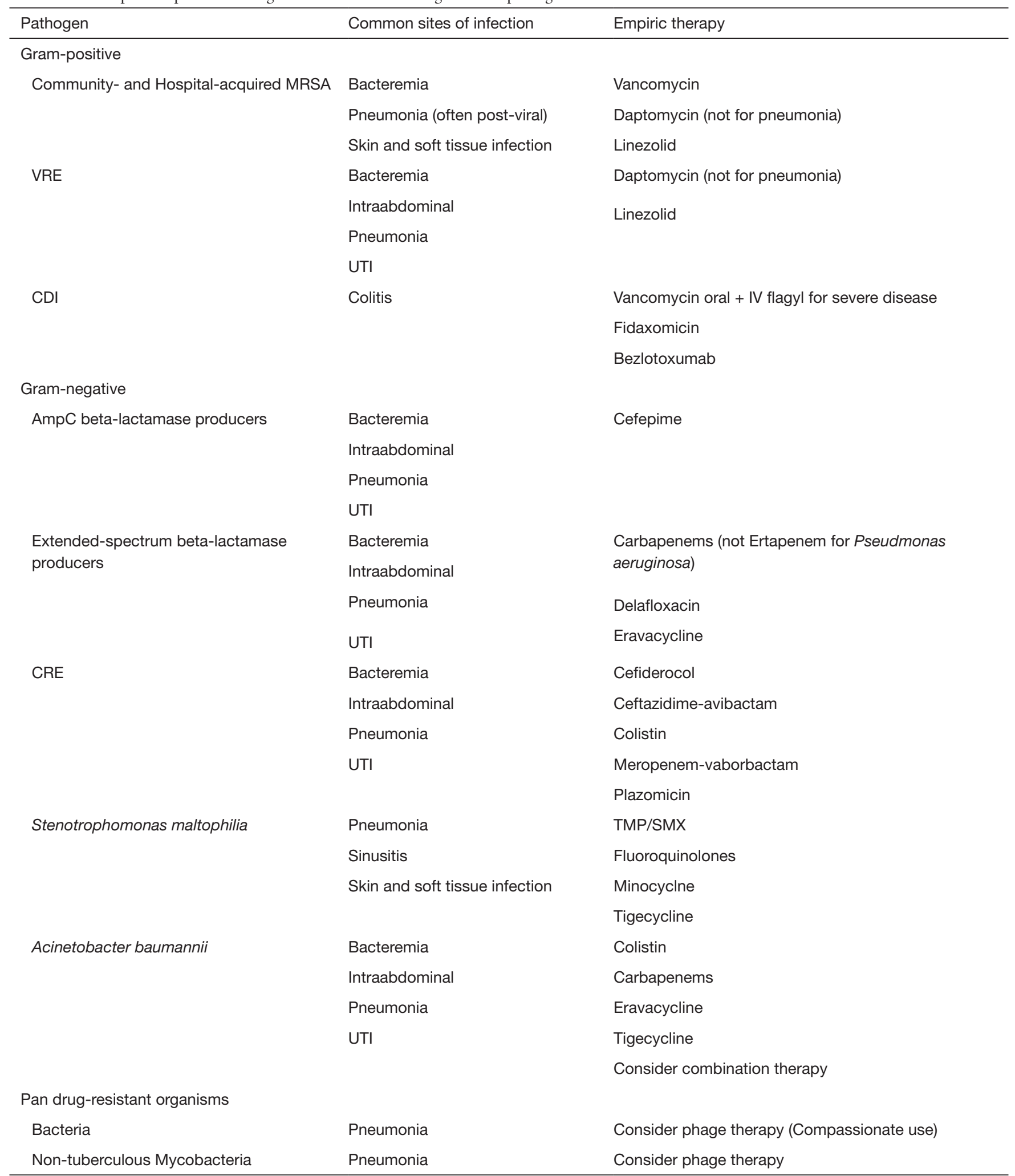

VRE, vancomycin-resistant Enterococci; UTI, urinary tract infection; CDI, clostridium difficile infection; CRE, carbapenem-resistant Enterobacteriaceae. 
infections (2 with PsAR, 1 with Burkholderia dolosa) (171). Lytic phages were selected against their isolates. The two patients with PsAR infection responded clinically and were discharged. The patient with $B$. dolosa initially responded, but later relapsed and died. Bacteriophage therapy has also been successfully used in treating a LTR with CF with a disseminated M. abscessus infection (172).

\section{Prevention}

Infection prevention is critical to reduce the morbidity and mortality associated with BIs in LTRs. This involves a detailed assessment of prior infections, vaccination status in the pre-transplant period, peri-transplant chemoprophylaxis, and reduction of infectious exposures.

\section{Pre-transplant screening}

During the transplant evaluation, it is important to review the patient's travel history, prior infections and exposures. This allows the clinician to have a complete understanding of a patient's risk factors in order to develop an appropriate plan to minimize infectious complications peri-transplant. Obtaining sputum samples for bacterial, fungal, and mycobacterial analysis can identify colonization patterns and help inform chemoprophylaxis (173). Of particular importance is screening for tuberculosis (TB). TB is 20-74 times more common in SOT recipients compared to the general population, although the incidence varies significantly by region (140). Post-transplant, active TB infection most commonly results from reactivation of previously latent disease, so identification and treatment of latent TB infection (LTBI) prior to transplant is recommended $(140,174)$. Screening of donors by Quantiferon TB testing has been shown to decrease the risk of donor-derived TB (175).

\section{Vaccination}

Vaccination is another important part of the pre-transplant management. All candidates undergoing evaluation for lung transplant should have their immunization status reviewed and assure that routine vaccinations are up to date. At adults with end-stage lung disease receive all vaccines recommended by the Center for Disease Control and Prevention (CDC) guidelines for immunocompetent patients with equivalent age, exposure history, and immune status (176). Protection of LTRs also requires vaccination of household members and close contacts with all recommended inactivated vaccines.

Necessary vaccines should be administered as early as possible pre-transplant as the immune response to vaccines is decreased in the setting of organ failure and immunosuppression (177). Live attenuated vaccines and inactivated vaccines should be administered at least 4 and 2 weeks prior to transplant, respectively (176). After transplant, the optimal time to vaccinate is not known. Poor immune response to vaccination occurs in the immediate post-transplant period in the setting of intense immunosuppression. Most centers wait 3-6 months after transplant when maintenance immunosuppression is reached to initiate vaccination (177). Live attenuated vaccines should be avoided, but inactivated vaccines can be safely administered.

In the studies of invasive pneumococcal disease by de Bruyn and Kumar, the vast majority of isolates in serotypes are covered by the PPSV23-associated serogroups (100\% and $85 \%$ respectively) $(110,111)$. Protection, however, is limited due to suboptimal vaccine responses. To improve protection, all vaccinees, immunocompetent or immunocompromised, should be vaccinated using a primeboost strategy against pneumococcal disease, receiving both the PCV13 and PPSV23 vaccines (176,177). PCV13 should be administered first followed by PPSV23 at least 8 weeks later. A booster dose of PPSV23 should be given 5 years later (177). If the vaccines are not given prior to transplant, they should be given 3-6 months following transplant when immunosuppression is at maintenance levels. Despite the availability of guidelines, a cross-sectional study of one transplant center found that only $62.4 \%$ of lung transplant candidates had received pneumococcal vaccination (178).

While SOT recipients can mount an immunologic response to vaccination, it is diminished compared to healthy controls $(47,179)$. Patients vaccinated against pneumococcus pre-transplant frequently have a decline in immunoglobulin levels, including anti-pneumococcal polysaccharide antibodies, in the first post-transplant year (46). On revaccination, there were still suboptimal responses seen, even when boosters were given a median of 4.4 years post-transplant. In one study of renal transplant recipients, vaccine response durability was similar amongst patients who have received the PPSV23 or the PCV7 vaccine (179). A retrospective study of LTRs found PCV7 was immunogenic, but there was no benefit from an additional PPSV23 dose (180). Several studies have investigated whether a prime-boost strategy (PCV7 followed by a 
booster with PPSV23 versus PPSV23 alone) may enhance immunogenicity post-transplant. In studies of kidney and liver transplant recipients, there was no significant difference in immunogenicity with either approach (181-183).

LTTs or candidates for lung transplant may also benefit from vaccination against Haemophilus influenzae type B (Hib), Neisseria meningitidis, and tetanus. There is limited data on the use of these vaccines in transplant patients, but in general, guidelines should be followed $(176,177)$.

Small case-control and cohort studies have implicated vaccinations in allograft. Most of the reports were in heart or kidney transplant recipients receiving seasonal influenza vaccine, particularly the H1N1 vaccine $(184,185)$. Larger studies have not shown any significant association. A recent systematic review and meta-analysis investigated rates of de novo donor-specific antibody (DSA) production and rejection after vaccination of SOT recipients (186). This review found no increased risk of DSA development, rejection, or graft failure among vaccinated patients. These studies support the safety and efficacy of vaccination in transplant populations $(178,187)$.

\section{Passive immunization}

There are no specific recommendations regarding the use of nonspecific intravenous immunoglobulin (IVIG) or pathogen-specific immunoglobulin preparations to prevent BI in LTRs. Uncontrolled studies of IVIG replacement in heart transplant recipients have shown benefit (188). Studies investigating the effects of IVIG replacement therapy for LTRs with HGG, however, have not shown any impact of IVIG on rates of infection, chronic lung allograft dysfunction, or survival $(189,190)$. Further study is needed in this area.

\section{Peri-transplant prophylaxis}

Peri-transplant infection can occur as a result of pathogens present in the donor, the recipient, or from new hospitalacquired pathogens. Microbiologic evaluation of samples from the donor lungs obtained via bronchoscopy are important for the management of post-transplant infections $(99,173)$. The majority of donor lungs are colonized, often with multiple organisms identified (100). While colonization of the donor lungs is common, the risk of subsequent recipient infection is relatively low when the infection is identified prior to procurement and proper prophylaxis is employed $(191,192)$. MDR bacteria, including methicillin-resistant Staphylococcus aureus (MRSA), Vancomycin-resistant Enterococcus (VRE), and MDR Gram-negative rods represent a major challenge in peritransplant management (193). CREs are emerging MDR pathogens that cause infection in $3-10 \%$ of SOT recipients in endemic areas $(194,195)$. Depending on transplant center location, the prevalence of MDR bacteria among donors ranges from $4.9 \%$ to $10.5 \%$ (192). Rates of MDR donor-derived infection are low, but the mortality can be higher when these infections are unknown at the time of procurement and appropriate prophylaxis is not given (196).

CF patients are known to be colonized with bacteria in both the upper and lower airways. The sinuses may serve also as a reservoir for bacteria that can spread to the lung allograft post-transplant $(194,197)$. Some centers endorse either pre- or post-transplant sinus surgery, although data is conflicting (57,197-199).

MRSA is certainly an important nosocomial pathogen, and prevention of MRSA colonization and infection is important for LTRs, as well as other surgical patients (200). Data from heart transplant recipients suggests that active surveillance for MRSA followed by selective decolonization can reduce surgical site infections (201). Modeling using data on LTRs with respect to the incidence of MRSA colonization post-LT, the risk of subsequent Staph. aureus infection, and estimates on the efficacy of decolonization with mupirocin and chlorhexidine suggested active surveillance for MRSA colonization and decolonization could reduce infections and save costs (202). Results of clinical trials in other SOTs have been conflicting. Currently active surveillance for MRSA, pre- and posttransplantation, followed by selective decolonization is not generally recommended by guidelines, although this can be considered if a site has high rates of MRSA infection (203). Rather, general infection control strategies to minimize risk of acquiring MDROs are recommended.

Finally, isoniazid is effective in preventing active TB in patients with LTBI (204).

\section{Minimizing risk}

Similar to all hospitalized patients, LTRs are at risk for nosocomial infections (200). Proper precautions, including basic hand hygiene, should always be used to minimize the risk for nosocomial infections and outbreaks. Other interventions, including chlorhexidine bathing, central line bundles, disinfection protocols, and antimicrobial stewardship, all help to reduce the incidence of nosocomial 
infections (204). Breaks in infection control measures have resulted in outbreaks of BIs in SOT populations $(205,206)$.

\section{Acknowledgments}

Funding: None.

\section{Footnote}

Provenance and Peer Review: This article was commissioned by the Guest Editor (Jonathan D'Cunha) for the series "Lung Transplantation: Past, Present, and Future" published in Fournal of Thoracic Disease. The article has undergone external peer review.

Conflicts of Interest: All authors have completed the ICMJE uniform disclosure form (available at: http:// dx.doi.org/10.21037/jtd-2021-12). The series "Lung Transplantation: Past, Present, and Future" was commissioned by the editorial office without any funding or sponsorship. The authors have no other conflicts of interest to declare.

Ethical Statement: All authors are accountable for all aspects of the work in ensuring that questions related to the accuracy or integrity of any part of the work are appropriately investigated and resolved.

Open Access Statement: This is an Open Access article distributed in accordance with the Creative Commons Attribution-NonCommercial-NoDerivs 4.0 International License (CC BY-NC-ND 4.0), which permits the noncommercial replication and distribution of the article with the strict proviso that no changes or edits are made and the original work is properly cited (including links to both the formal publication through the relevant DOI and the license). See: https://creativecommons.org/licenses/by-nc-nd/4.0/.

\section{References}

1. Burguete S, Diego M, Levin F, et al. Lung transplant infection. Respirology 2013;18:22-38.

2. Alexander BD, Tapson VF. Infectious complications of lung transplantation. Transpl Infect Dis 2001;3:128-37.

3. Witt CA, Meyers BF, Hachem RR. Pulmonary nfections following lung transplantation. Thorac Surg Clin 2012;22:403-12.

4. Gagliotti C, Morsillo F, Moro ML, et al. Infections in liver and lung transplant recipients: a national prospective cohort. Eur J Clin Microbiol Infect Dis 2018;37:399-407.

5. van Delden C, Stampf S, Hirsch H, et al. Burden and timeline of infectious diseazse int he first year after solid orgran transplantation in the Swiss Transplant cohort study. Clin Infect Dis 2020. doi: 10.1093/cid/ciz1113.

6. Wojarski J, Ochman M, Medrala W, et al. Bacterial infections during hospital stay and their impact after lung transplantation: A single-center study. Transplant Proc 2018;50:2064-9.

7. Speich R, van der Bij W. Epidemiology and management of infections after lung transplantation. Clin Infect Dis 2001;33 Suppl 1:S58-65.

8. Maurer JR, Tullis DE, Grossman RF, et al. Infectious complications following isolated lung transplantation. Chest 1992;101:1056-9.

9. Zander DS, Baz MA, Visner GA, et al. Analysis of early deaths after isolated lung transplantation. Chest 2001;120:225-32.

10. Deusch E, End A, Griomm M, et al. Early bacterial infections in lung transplant recipients. Chest 1993;104:1412-6.

11. Husain AN, Siddiqui MT, Reddy VB, et al. Postmortem findings in lung transplant recipients. Mod Pathol 1996;9:752-61.

12. Danziger-Isakov LA, Sweet S, Delamorena M, et al. Epidemiology of bloodstream infections in the first year after prediatric lung transplantation. Pediatr Infect Dis J 2005;24:324-30.

13. Nosotti M, Tarsia P, Mortacchi LC. Infections after lung transplantation. J Thorac Dis 2018;10:3849-68.

14. Parada MT, Alba A, Sepulveda C. Bronchiolitis obliterans syndrome development in lung transplantation patients. Transplant Proc 2010;42:331.

15. Belperio J, Palmer SM, Weight SS. Host-pathogen interactions and chronic lung allograft dysfunction. Ann Am Thorac Soc 2017;14:S242-6.

16. Shields RK, Clancy CJ, Minces LR, et al. Epidemiology and outcomes of deep surgical site infections following lung transplantation. Am J Transplant 2013;13:2137-45.

17. Fishman JA. Infection in solid-organ transplant recipients. N Engl J Med 2007;357:2601-14.

18. Patel R, Paya CV. Infections in solid-organ transplant recipients. Clin Microbiol Rev 1997;10:86-124.

19. Parada MT, Alba A, Sepulveda C. Early and late infections in lung transplantation patients. Transplant Proc 2010;42:333-5.

20. Wahidi MM, Willner DA, Snyder LD, et al. Diagnosis and outcome of early pleural space infection following lung 
transplantation. Chest 2009;135:484-91.

21. San Juan R, Aguado JM, Diaz-Pedroche C, et al. Incidence, clinical characteristics, and risk factors of late infection in solid organ transplant recipients: data from the RESITRA study group. Am J Transplant 2007;7:964-71.

22. TebanoG, Geneve C, Tanaka S, et al. Epidemiology and risk factors of multidrug-resistant bacteria in respiratory samples after lung transplantation. Transpl Infect Dis 2016;18:22-30.

23. Shields RK, Clancy CJ, Minces LR, et al. Staphylococcus aureus infections in the early period after lung transplantation. J Heart Lung Transplant 2012;31:1199-206.

24. Bui KT, Mehta S, Khuu TH, et al. Extended spectrum $\beta$-lactamase-producing Enterobacteriaceae infection in heart and lung transplant recipients and in mechanical circulatory support recipients. Transplantation 2014;97:590-4.

25. Biderman P, Bugaevsky Y, Ben-Zvi H, et al. Multidrugresistant Acinetobacter baumannii infections in lung transplant patients in the cardiothoracic intensive care unit. Clin Transplant 2015;29:756-62.

26. Oh DH, Kim YC, Kim EJ, et al. Multidrug-resistant Acinetobacter buamannii infection in lung transplant recipients: risk factors and prognosis. Infect Dis (Lond) 2019;51:493-501.

27. Monteagudo Vela M, Zych B, Garcia Saez D, et al. Fatal infection with Elisabethkingia miricola after lung transplantation. J Hosp Infect 2018;100:e259-60.

28. Los-Arcos I, Len O, Martín-Gómez MT, et al. Clinical Characteristics and Outcome of Lung Transplant Recipients with Respiratory Isolation of Corynebacterium spp. J Clin Microbiol 2018;56:e00142-18.

29. Dixit A, Alexandrescu S, Boyer D, et al. Mycoplasma hominis empyema in an 18-year old stem cell and lung transplant recipient: Case report and review of the literature. J Pediatric Infect Dis Soc 2017;6:e173-6.

30. Hagyia H, Yoshida H, Yammamaoto N, et al. Mycoplasma hominis peraortic abscess following heart-lung transplantation. Transpl Infect Dis 2017;19.

31. Cusini A, Beguelin C, Stampf S, et al. Clostirdium difficile infection is associated with graft loss in solid organ transplant recipients. Am J Transplant 2018;18:1745-54.

32. Lee JT, Kelly RF, Hertz MI, et al. Clostridium difficile infection increases mortality risk in lung transplant recipients. J Heart Lung Transplant 2013;32:1020-6.

33. Dorgan DJ, Hadjiliadis D. Lung transplantation in patients with cystic fibrosis: a special focus to infections and comorbidities. Expert Rev Respir Med 2014;8:315-26.
34. D'Ovidio F, Keshavjee S. Gastroesophageal reflux and lung transplantation. Dis Esophagus 2006;19:315-20.

35. Duarte AG, Terminella L, Smith JT, et al. Restoration of cough reflex in lung transplant recipients. Chest 2008;134:310-6.

36. Fallis RJ, Jablonski L, Moss S, et al. Infectious complciations of bronchial stenosis in lung transplant recipients. Transpl Infect Dis 2019;21:e13100.

37. Etienne B, Mornex JF. Immunological aspects of lung transplantation. Rev Mal Respir 1996;13:S15-S22.

38. Hodge G, Hodge S, Reynolds PN, et al. Airway infection in stable lung transplant patients is associated with decreased intracellular T-helper type 1 proinflammatory cytokines in bronchoalveolar lavage T-cell subsets. Transpl Infect Dis 2008;10:99-105.

39. Husain S, Raza K, Pilewski JM, et al. Experience with immune monitoring in lung transplant recipients: Correlation with low immune function with infection. Transplantation 2009;87:1852-7.

40. Bhorade SM, Janata K, Vigneswaran WT, et al. Cylex ImmuKnow assay levels are lower in lung transplant recipients with infection. J Heart Lung Transplant 2008;27:990-4.

41. Goldfarb NS, Avery RK, Goormastic M, et al. Hypogammaglobulinemia in lung transplant recipients. Transplantation 2001;71:242-6.

42. Robertson J, Elidemir O, Saz EU, et al. Hypogammaglobulinemia: Incidence, risk factors, and outcomes following pediatric lung transplantation. Pediatr Transplant 2009;13:754-9.

43. Florescu DF, Kalil AC, Qiu F, et al. Does increasing immunoglobuin levels impact survival in solid organ transplant recipients with hypogammaglobulinemia? Clin Transplant 2014;28:1249-55.

44. Florescu DF, Kalil AC, Qui F, et al. What is the impact of hypogammaglobulinemia on the rate of infections and survival in solid organ transplantation? A meta-anlysis. Am J Transplant 2013;13:2601-10.

45. RK Avery, Blumberg EA. Hypogammaglobulinemia: Time to reevaluate? Am J Transplant 2013;13:2517-8.

46. van Kessel DA, Hoffman TW, Kwakkel-van Erp JM, et al. Long-term follow-up of humoral immune status in adult lung transplant recipients. Transplantation 2017;101:2477-83.

47. Sarmiento E, Cifrian J, Calahorra L, et al. Monitoring of early humoral immunity to identify lung recipients at risk for the development of serious infections: A multicenter prospective study. J Heart Lung Transplant 
2018;37:1001-12.

48. Yip NH, Lederer DJ, Kawut SM, et al. Immunoglobulin $G$ levles before and after lung transplantation. Am J Respir Crit Care Med 2006;173:917-21.

49. Murthy SC, Avery RK, Budev M, et al. Low pretransplant IgA level is associateed with early post-lung transplant seromucous infection. J Thorac Cardiovasc Surg 2018;156:882-91.e8.

50. Fernandez-Ruiz M, Kumar D, Humar A. Clinical immune-monitoring strategies for predicting infection risk in solid organ transplantation. Clin Transl Immunology 2014;3:e12.

51. Corris PA. Lung transplantation for cystic fibrosis and bronchiectasis. Semin Respir Crit Care Med 2013;34:297-304.

52. Lechtzin N, Majnu J, Merlo C, et al. Outcomes of adults with cystic fibrosis infected with antibiotic-resistant Pseudomonas aeruginosa. Respiration 2006;73:27-33.

53. Lechtzin N, Majnu J, Merlo C, et al. Outcomes of adults with cystic fibrosis infected with antibiotic-resistant Pseudomonas aeruginosa. Respiration 2006;73:27-33.

54. Shteinberg M, Raviv Y, Bishara J, et al. The impact of fluoroquinolone resistance of Gram-negative bacteria in respiratory secretions on the outcome of lung transplant (non-cystic fibrosis) recipients. Clin Transplant 2012;26:884-90.

55. Beaume M, Kohler T, Greub G, et al. Rapid adaptation drives invasion of airway donor microbiota by Pseudomonas after lung transplantation. Sci Rep 2017;7:40309.

56. Vital D, Hofer M, Benden C, et al. Impact of sinus surgery on pseudomonal airway colonization, bronchioloitis obilterans syndrome and survival in cystic fibrosis lung transplant recipients. Respiration 2013;86:25-31.

57. Syed SA, Whelan FJ, Waddell B, et al. Reemergence of lower-airway mcirobiota in lung transplant patients with cystic fibrosis. Ann Am Thorac Soc 2016;13:2132-42.

58. Shoham S, Shah PD. Impact of multidrug-resistant organisms on patients considered for lung transplantation. Infect Dis Clin North Am 2013;27:343-58.

59. Stephenson AL, Sykes J, Berthiaume Y, et al. Clinical and demographic factors associated with post-lung transplantation survival in individuals with cystic fibrosis. J Heart Lung Transplant 2015;34:1139-45.

60. Alexander BD, Petzold EW, Reller EB, et al. Survival after lung transplantation in cystic fibrosis patients infected with Burkholderia cepacia complex. Am J Transplant 2008;8:1025-30.
61. Dobbin C, Maley M, Harkness J, et al. The impact of pan-resistant bacterial pathogens on survival after lung transplantation. J Hosp Infect 2004;56:277-82.

62. Lobo LJ, Tulu A, Aris RM, et al. Pan-resistant Achromobacter xylosoxidans and Stenotrophomonas maltophilia infection in cystic fibrosis does not reduce survival after lung transplantation. Transplantation 2015;99:2196-202.

63. Lobo LJ, Noone PG. Respiratory infections in patients with cystic fibrosis undergoing lung transplantation. Lancet Respir Med 2014;2:73-82.

64. Gilljam M, Nystrom U, Dellgren G, et al. Survival after lung transplantation for cystic fibrosis in Sweden. Eur J Cardiothorac Surg 2017;51:571-6.

65. Jankovic Makek M, Pavlisa G, Jakpovic M, et al. Early onset of nontuberculous mycobacterial pulmonary disease contributes to the lethal outcome in lung transplant recipients: report of two cases and a review of the literature. Transpl Infect Dis 2016;18:112-9.

66. Knoll BM, Kappagoda S, Gill RR, et al. Non-tuberculous mycobacterial infection among lung transplant recipients: a 15-year cohort study. Transpl Infect Dis 2012;14:452-60.

67. Osmani M, Sotello D, Alvarez S, et al. Mycobacterium abscessus infections in lung transplant recipients: 15-year experience from a single institution. Transpl Infect Dis 2018;20:e12835.

68. Shah SK, McAnally KJ, Seoane L, et al. Analysis of pulmonary non-tuberculous mycobacterial infections after lung transplantation. Transpl Infect Dis 2016;18:585-91.

69. Hamad Y, Pilewski JM, Moreell M, et al. Outocmes in lung transplant recipients with Mycobacterium abscessus infection: a 15-year experience from a large tertiary care center. Transplant Proc 2019;51:2035-42.

70. Lobo LJ, Chang LC, Esther CR, et al. Lung transplant outcomes in cystic fibrosis patients with pre-operative Mycobacterium abscessus respiratory infections. Clin Transplant 2013;27:523-9.

71. Perez AA, Singer JP, Schwartz BS, et al. Management and clinical outcomes after lung transplantation in patients with pre-transplant Mycobacterium abscessus infection: A single center experience. Transpl Infect Dis 2019;21:e13084.

72. Vindigni SM, Surawicz CM. The gut microbiome: a clinically significant player in transplantation? Expert Rev Clin Immunol 2015;11:781-83.

73. Cribbs SK, Beck JM. Microbiome in the pathogenesis of cystic fibrosis and lung transplannt-related disease. Transl Res 2017;179:84-96. 
74. Becker J, Poroyko V, Bhorade S. The lung microbiome after lung transplantation. Expert Rev Respir Med 2014;8:221-31.

75. Charlson ES, Diamond J, Bittinger K, et al. Lungenriched organisms and aberrant bacterial and fungal respiratory microbiota after lung transplant. Am J Respir Crit Care Med 2012;186;536-45.

76. Palmer SM, Burch L, Davis R. The role of innate immunity in acute allograft rejection after lung transplantation. Am J Respir Crit Care Med 2003;168:628-32.

77. Ohmann EL, Brooks MM, Webber SA, et al. Association of genetic polymorphisms and risk of late posttransplantation infection in pediatric heart recipients. $\mathrm{J}$ Heart Lung Transplant 2010;29:1342-51.

78. Cunha C, Aversa F, Lacerda J, et al. Genetic PTX3 deficiency and aspergillosis in stem-cell transplanta-tion. N Engl J Med 2014;370:421-2.

79. Chiarini M, Sabelli C, Melotti P, et al. PTX3 genetic variations affect the risk of Pseudomonas aeruginosa airway colonization in cystic fibrosis patients. Genes Immun 2010;11:665-70.

80. Hamon Y, Jaillon S, Person C, et al. Proteolytic cleavage of the long pentraxin PTX3 in the airways of cystic fiborsis patients. Innate Immun 2013;19:611-22.

81. Yildrim Y, Pecha S, Deuse T, et al. Severe bacterial superinfection based on influenza A (H1N1) pneu-monia in a heart-lung transplant recipient. J Thorac Cardiovasc Srg 2013;61:255-7.

82. Mason DP, Thuita L, Nowicki ER, et al. Should lung transplantation be performed for patients on me-chanical respiratory support? The US experience. J Thorac Cardiovasc Surg 2010;139:765-73.e1.

83. Singer JP, Blanc PD, Hoopes C, et al. The impact of pretransplant mechanical ventilation on short and long-term survival after lung transplantation. Am J Transplant 2011;11:2197-204.

84. Koval CE, Farr M, Krisl J, et al. Heart or lung transplant outcomes in HIV-infected recipients. J Heart Lung Transplant 2019;38:1296-305.

85. Speich R, van der Bij W. Epidemiology and management of infections after lung transplantation. Clin Infect Dis 2001;33 Suppl 1:S58-65.

86. MaurerJR, Tullis DE, Grossman RF, et al. Infectious complications following isolated lung transplanta-tion. Chest 1992;101:1056-9.

87. Heng D, Sharples LD, McNeil K, et al. Bronchiolitis obliterans syndrome: incidence, natural history, prognosis, and risk factors. J Heart Lung Transplant 1998;17:1255-63.
88. Palmer SM, Burch L, Davis, et al. The role of innate immunity in acute allograft rejection after lung transplantation. Am J Resp Crit Care Med 2003;168:628-32.

89. Wiebe K, Fraund S, Steinmuller C, et al. Rate cytomegalovirus and Listeria monocytogenes infection enhance chornic rejection after allogenic rate lung transplantation. Transpl Int 2005;18:1166-74.

90. Meyer KC, Nunley DR, Dauber JH, et al. Neutrophils, unopposed neutrophil elastase, and alpha-1 anti-protease defenses following human lung transplantation. Am J Resp Crit Care Med 2001;164:97-102.

91. Nunley DR, Grgurich W, Iacono A, et al. Allograft colonization and infections with Pseudomonas in cystic fibrosis lung transplant recipients. Chest 1998;113;1235-43.

92. Gottlieb J, Mattner F, Weissbrodt H, et al. Impact of graft colonization with gram-negative bacteria after lung transplantation on the development of bronchiolitis obliterans syndrome in recipients with cystic fibrosis. Respir Med 2009;103:743-9.

93. Vos R, Vanaudenaerde BM, Geudens N, et al. Pseudomonal airway colonisation: Risk factor for bronchiolitis obliterans syndrome after lung transplantation? Eur Respir J 2008;31:1037-45.

94. Orfanos S, Gomez C, Baron S, et al. Impact of gram negative bacteria airway recolonization on the oc-currence of lung allograft dysfunction after lung transplantation in a population of cystic fibrosis patients. BMC Microbiol 2018;18:88.

95. Vos R, Blondeau K, Vanaudenaerde BM, et al. Airway colonization and gastric aspiration after lung transplantation: Do birds of a feather flock together? J Heart Lung Transplant 2008;27:843-9.

96. Yamamoto S, Nava RG, Zhu J, et al. Cutting edge: Pseudomonas aeruginosa abolishes established lung tolerance by stimulating B7 expression on neutrophils. J Immunol 2012;189:4221-5.

97. Charpin JM, Stern M, Lebrun G, et al. Increased endothelin-1 associated with bacterial infection in lung transplantation. Transplantation 2001;71:1840-7.

98. Gunderson CC, Gupta MR, Lopez F, et al. Clostridium difficile colitis in lung transplantation. Transpl Infect Dis 2008;10:245-51.

99. Mohanka MR, Mehta AC, Budey MM, et al. Impact of bedside bronchsocopy in ciritically ill lung tgrans-plant recipients. J Bronchology Interv Pulmonol 2014;21:199-207.

100.Desmard M, Benbara A, Boudinet S, et al. Post-operative kinetics of procalcitonin after lung transplanta-tion. J Heart Lung Transplant 2015;34:189-94. 
101. Campos S, Caramori M, Teixeira R, et al. Bacteria 1 and fungal pneumonias after lung transplantation. Transplant Proc 2008;40:822-4.

102. Christie JD, Edwards LB, Kucheryavaya AY, et al. The registry of the International Society for Heart and Lung Transplantation: Twenty-ninth official adult lung and heart-lung report-2012. J Heart Lung Transplant 2012;31:311-9.

103. Fishman JA. Infection in solid-organ transplant recipients. N Engl J Med 2007;357:2601-14.

104.Aguilar-Guisado M, Givalda J, et al. Pneumonia after lung transplantation in the RESITRA Cohort: A multicenter prospective study. Am J Transplant 2007;7:1989-96.

105. Tanaka S, Geneve C, Tebano G, et al. Morbidity and mortality related to pneumonia and tracheobron-chitis in ICU after lung transplantation. BMC Pulm Med 2018;18:43.

106. Valentine VG, Bonvillain RW, Gupta MR, et al. Infections in lung allograft recipients: ganciclovir era. J Heart Lung Transplant 2008;27:528-35.

107. Riera J, Baldira J, Ramirez S, et al. Gastroparesis following lung transplantation: Risk factor for pneumo-nia. Eur Respir J 2015;46:PA2644.

108. Fishman JA, Issa NC. Infection in Organ Transplantation: risk factors and evolving patterns of infect ion. Infect Dis Clin North Am 2010;24:273-83.

109. Kim SY, Shin JA, Cho EN, et al. Late respiratory infection after lung transplantation. Tuberc Respir Dis (Seoul) 2013;74:63-9.

110.de Bruyn G, Whelan TP, Mulligan MS, et al. Invasive pneumococcal infections in adult lung transplant recipients. Am J Transplant 2004;4:1366-71.

111.Kumar D, Humar A, Plevneshi A, et al. Invasive pneumococcal disease in solid organ transplant recipients --10-year prospective e population surveillance. Am J Transplant 2007;7:1209-14.

112.Tkatch LS, Kusne S, Irish WD, et al. Epidemiology of Legionella pneumonia and factors associated with legionella-related mortality at a tertiary care center. Clin Infect Dis 1998;27:1479-86.

113. Nichols L, Strollo DC, Kusne S. Legionellosis in a lung transplant recipient obscured by cytomegalovirus infection and Clostridium difficile colitis. Transpl Infect Dis 2002;4:41-5.

114. Bangsborg JM, Uldum S, Jensen JS, et al. Nosocomial legionellosis in three heart-lung transplant pa-tients: Case reports and environmental observations. Eur J Clin Microbiol Infect Dis 1995;14:99-104.
115.Schwarzmann SW, Adler JL, Sullivan RJ, et al. Bacterial pneumonia during the Hong Kong influenza epidemic of 1968-01969. Arch Intern Med 1971;127:1037-41.

116. Simonsen L. The global impact of influenza on morbidity and mortality. Vaccine 1999;17:S3-S10.

117.Peltola VT, Murti KG, McCullaer JA. Influenza virus neuraminidase contributes to secondary bacterial pneumonia. J Infect Dis 2005;192:249-57.

118. Hageman JC, Uyeki TM, Francis JS, et al. Severe community acquired pneumonia due to Staphylococcus aureus, 2003-2004 influenza season. Emerg Infect Dis 2006;12:894-9.

119. Ruiz I, Gavalda J, Monforte V, et al. Donor-to-host transmission of bacterial and fungal infections in lung transplantation. Am J Transplant 2006;6:178-82.

120. Bunsow E, Los-Arcos I, Martin-Gómez MT, et al. Donorderived bacterial infections in lung transplant recipients in the era of multidrug resistance. J Infect 2020;80:190-6.

121. Bonde PN, Patel ND, Borja MC, et al. Impact of donor lung organisms on post-lung transplant pneumo-nia. J Heart Lung Transplant 2006;25:99-105.

122. Dobbin C, Maely M, Harkness J, et al. The impact of pan-resistant bacteria after lung transplantation in cystic fibrosis: Results from a single large referral center. J Hosp Infect 2004;56:277-82.

123. Howell CK, Paciullo CA, Lyon GM, et al. Effective of perioperative donor and recipients respiratory bacterial cultures on early post-transplant outcomes in lung transplant recipients. Transpl Infect Dis 2017;19.

124. Smith SR, Foweraker J, Hamilton D, et al. Impact of antibiotic-resistant Pseudomonas on the survival of cystic fibrosis (CF) patients following heart-lung transplantation. J Heart Lung Transplant 2001;20:224.

125.Aris RM, Gilligan PH, Neuringer IP, et al. The effects of panresistant bacteria in cystic fibrosis patients on lung transplant outcomes. Am J Resp Crit Care Med 1997;155:1699-704.

126. Palmer SM, Alexander BD, Sanders LL, et al. Significance of blood stream infection after lung trans-plantation: analysis of 176 consecutive patients. Transplantation 2000;69:2360.

127. Riera J, Caralt B, Lopez I, et al. Ventilator-associated respiratory infection following lung transplantation. Eur Respir J 2015;45:726-37.

128. Nunley DR, Grgurich WF, Keenan RJ, et al. Empyema complicating successful lung transplantation. Chest 1999; $115: 1312$.

129.Herridge MS, de Hoyos AL, Chaparro C, et al. Pleural 
complications in lung transplant recipients. J Thorac Cardiovasc Surg 1995;110:22.

130. Risnes I, Abdelnoor M, Almdahl SM, et al. Mediastinitis after coronary artery bypass grafting: risk fac-tors and long-term survival. Ann Thorac Surg 2010;89:1502.

131.Baldwin RT, Radovancevic B, Sweeney MS, et al. Bacterial mediastinitis after heart transplantation. J Heart Lung Transplant 1992;11:545-9.

132.Abid Q, Nkere UU, Hasan A, et al. Mediastinitis in heart and lung transplantation: 15 years experience. Ann Thorac Surg 2003;75:1565-71.

133. Husain S, Chan KM, Palmer SM, et al. Bacteremia in lung transplant recipients in the current era. Am J Transplant 2006;6:3000.

134. Alsaeed M, Husain S. Infections in heart and lung transplant recipients. Crit Care Clin 2019;35:75-93.

135. Abbo L, Grossi PA. Surgical site infections: guidelines from the American Society of Transplantation Infectious Diseases community of practice. 2019.

136. Anesi JA, Blumberg EA, Abbo LM. Perioperative antibiotic prophylaxis to prevent surgical site infections in solid organ transplantation. Transplantation 2018;102:21-34.

137.Mullane KM, Dubberke ER; AST ID Community of Practice. Management of Clostridioides (formerly Clostridium) difficile infection (CDI) in solid organ transplant recipients: Guidelines from the American Society of Transplantation Community of Practice. Clin Transplant 2019;33:e1364.

138. Malouf MA, Glanville AR. The spectrum of mycobacterial infection after lung transplantation. Am J Respir Crit Care Med 1999;160:1611-6.

139. Bumbacea D, Arend SM, Eyuboglu F, et al. The risk of tuberculosis in transplant candidates and recipients: a TBNET consensus statement. Eur Respir J 2012;40:990-1013.

140.Muñoz P, Rodríguez C, Bouza E. Mycobacterium tuberculosis infection in recipients of solid organ transplants. Clin Infect Dis 2005;40:581-7.

141.Singh N, Paterson DL. Mycobacterium tuberculosis infection in solid-organ transplant recipients: impact and implications for management. Clin Infect Dis 1998;27:1266-77.

142. Dromer C, Nashef SA, Velly JF et al. Tuberculosis in transplanted lungs. J Heart Lung Transplant 1993;12:924-7.

143. Morales P, Briones A, Torres JJ, et al. Pulmonary tuberculosis in lung and heart-lung transplantation: fifteen years of experience in a single center in Spain. Transplant Proc 2005;37:4050-5.
144. Bravo C, Roldan J, Roman A, et al. Tuberculosis in lung transplant recipients. Transplantation 2005;79:59-64.

145. Winthrop KL, Kubak BM, Pegues DA, et al. Transmission of mycobacterium tuberculosis via lung trans-plantation. Am J Transplant 2004;4:1529-33.

146. Doucette K, Fishman J. Nontuberculous mycobacterial infection in hematopoietic stem cell and solid organ transplant recipients. Clin Infect Dis 2004;38:1428-39.

147. Chernenko SM, Humar A, Hutcheon M, et al. Mycobacterium abscessus infections in lung transplant recipients: The international experience. J Heart Lung Transplant 2006;25:1447-55.

148. Fairhurst RM, Kubak BM, Shpiner RB, et al. Mycobacterium abscesses empyema in a lung transplant recipient. J Heart Lung Transplant 2002;21:391-4.

149. Garrison AP, Morrise M, Lewis S, et al. Mycobacterium abscessus infection in solid organ transplant re-cipients: Report of three cases and review of the literature. Transpl Infect Dis 2009;11:541-8.

150.Husain S, McCurry K, Dauber J, et al. Nocardia infection in lung transplant recipients. J Heart Lung Transplant 2002;21:354-9.

151. Khan BA, Duncan M, Reynolds J, et al. Nocardia infection in lung transplant recipients. Clin Transplant 2008;22:562-6.

152.Le Lay G, Martin F, Leroyer C, et al. Rhodococcus equi causing bacteraemia and pneumonia in a pulmo-nary transplant patient. J Infect 1996;33:239-40.

153. Fernandez R, Chi M, Ison M, et al. Sequelae of donorderived mollicutes in lung recipients. Am J Resp Crit Care Med 2017;195:687-9.

154.Fernandez R, Ratliff A, Crabb D, et al. Ureaplsasma transmitted from donor lungs in pathogenic after lung transplantation. Ann Thorac Surg 2017;103:670-71.

155. Bharat A, Budinger S, Eson MG. Donor-derived ureaplasma is a potentially lethal infection in lung allograft recipients. J Heart Lung Transplant 2017;36:917-8.

156. Graetz R, Mweyer R, Shehab K, et al. Successful resolution of hyperammonemia following hematopoiet-ic cell transplantation with directed therapy of Ureaplasma parvum infection. Transpl Infect Dis 2018;20:e12839.

157. Sopirala MM, Pope-Harman A, Nunley DR, et al. Multidrug-resistant Acinetobacter baumannii pneu-monia in lung transplant recipients. J Heart Lung Transplant 2008;27:804-7.

158.Patel G, Perez F, Bonomo RA. Carbapenem-resistant Enterobacteriaceae and Acinetobacter baumannii: Assessing their impact on organ transplantation. Curr Opin Organ Transplant 2010;15:676-82. 
159. Mattner F, Fisher S, Weissbrodt H, et al. Post-operative nosocomial infections after lung and heart transplantation. J Heart Lung Transplant 2007;26:241-9.

160. Herati RS, Blumberg EA. Losing ground: multidrugresistant bacterial in solid-organ transplantation. Curr Opin Infect Dis 2012;25:445-9.

161. Whiddon AR, Sdawson KL, Fuentes A, et al. Postoperative antimicrobials aafter lung transplantation and the development of multidrug-rfesistant bacterial and Clostridium difficile infections: an analysis of 500 noncystic fibrosis lung transplant recipients. Clin Transplant 2016;30:767-73

162. Carillo C, Pecoraro Y, Poggi C, et al. Colistin-based treatment of multidrug-resistant Gram-negative pulmonary infections after lung transplantation. Transplant Proc 2019;51:202-5.

163.Jean SS, Gould IM, Lee WS, et al. New drugs for multidrug-resistant Gram-negative organisms: Time for stewardship. Drugs 2019;79:705-14.

164.Zhanel GG, Golden AR, Zelenitsky S, et al. Cefiderocol: A siderophore cephalosporin with activity against carbapenem-resistant and multidrug-resistant Gramnegative bacilli. Drugs 2019;79:271-89.

165. Daccò V, Claut L, Castellazzi L, et al. Successful ceftazidime/avibactam treatment of post-surgery Burkholderia multivorans genomovar II bacteremia and brain abscess in a young lung transplanted wom-en with cystic fibrosis. Transpl Infect Dis 2019;21:e13082.

166. Aguado JM, Silva JT, Fernandez-Ruiz M, et al. Management of multidrug-resistant Gram negative bacilli infections in solid organ transplant recipients: SET/ GESITRA-SEIMC/REIPI. Transplant Rev (Orlando) 2018;32:36-57.

167.Janssens W, Van Raemdonck D, Dupont L, et al. Listeria pleuritis 1 week after lung transplantation. J Heart Lung Transplant 2006;25:734.

168. Weinstock DM, Brown AE. Rhodococcus equi: An emerging pathogen. Clin Infect Dis 2002;34:1379-85.

169. Nahid P, Dorman SE, Alipanah N, et al. Official American Thoracic Society/Centers for Disease Control and Prevention/Infectious Diseases Society of America Clinical Practice Guidelines: Treatment of Drug-Susceptible Tuberculosis. Clin Infect Dis 2016;63:e147-95.

170. Griffith DE, Aksamit T, Brown-Elliott BA, et al. An Official ATS/IDSA Statement: Diagnosis, Treat-ment, and Prevention of Nontuberculous Mycobacterial Diseases. Am J Respir Crit Care Med 2007;175:367-416.

171.Aslam S, Courtwright AM, Koval C, et al. Early clinical experience of bacteriophage therapy in 3 lung transplant recipients. Am J Transplant 2019;19:2631-9.

172. Dedrick RM, Guerrero-Bustamante CA, Garlena RA, et al. Engineered bacteriophages for treatment of a patient with disseminated drug-resistant Mycobacterium abscessus. Nat Med 2019;25:730-33.

173. Fischer SA, Lu K; AST Infectious Diseases Community of Practice. Screening of donor and recipient in solid organ transplantation. Am J Transplant 2013;13 Suppl 4:9-21.

174. Subramanian AK, Morris MI; AST Infectious Diseases Community of Practice. Mycobacterium tuber-culosis infections in solid organ transplantation. Am J Transplant. 2013;13 Suppl 4:68-76.

175. Tabarsi P, Yousefzadeh A, Najafizadeh K, et al. Performance of quantiferon TB Gold test in detecting latent tuberculosis infection in brain-dead organ donors in Iran: a brief report. Saudi J Kidney Dis Transpl 2014;25:1240-3.

176. Rubin LG, Levin MJ, Ljungman P, et al. 2013 IDSA clinical practice guideline for vaccination of the immunocompromised host. Clin Infect Dis 2014;58:309-18.

177. Danziger-Isakov L, Kumar D; AST ID Community of Practice. Vaccination of solid organ transplant candidates and recipients: Guidelines from the American society of transplantation infectious diseases community of practice. Clin Transplant 2019;33:e13563.

178. Gasink LB, Wurcell AG, Kotloff RM, et al. Low prevalence of prior streptococcus pneumoniae vaccination among potential lung transplant candidates. Chest 2006;130:218-21.

179.Dendle C, Stuart RL, Mulley WR, et al. Pneumococcal vaccination in adult solid organ transplant recipients: $A$ review of current evidence. Vaccine 2018;36:6253-61.

180.Kumar D, Welsh B, Siegal D, et al. Immunogenicity of pneumococcal vaccine in renal transplant recipients--three year follow-up of a randomized trial. Am J Transplant 2007;7:633-8.

181. Gattringer R, Winkler H, Roedler S, et al. Immunogenicity of a combined schedule of 7-valent pneumococcal conjugate vaccine followed by a 23 -valent polysaccharide vaccine in adult recipients of heart or lung transplants. Transpl Infect Dis 2011;13:540-4.

182. Kumar D, Chen MH, Wong G, et al. A randomized, double-blind, placebo-controlled trial to evaluate the primeboost strategy for pneumococcal vaccination in adult liver transplant recipients. Clin Infect Dis 2008;47:885-92.

183. Tobudic S, Plunger V, Sunder-Plassmann G, et al. Randomized, single blind, controlled trial to evaluate the 
prime-boost strategy for pneumococcal vaccination in renal transplant recipients. PLoS One 2012;7:e46133.

184. Katerinis I, Hadaya K, Duquesnoy R, et al. De novo anti-HLA antibody after pandemic $\mathrm{H} 1 \mathrm{~N} 1$ and seasonal influenza immunization in kidney transplant recipients. Am J Transplant 2011;11:1727-33.

185. Schaffer SA, Husain S, Delgado DH, et al. Impact of adjuvanted $\mathrm{H} 1 \mathrm{~N} 1$ vaccine on cell-mediated rejection in heart transplant recipients. Am J Transplant 2011;11:2751-4.

186. Mulley WR, Dendle C, Ling JEH, et al. Does vaccination in solid-organ transplant recipients result in adverse immunologic sequelae? A systematic review and metaanalysis. J Heart Lung Transplant 2018;37:844-52.

187.Zand MS. Safety and efficacy of influenza vaccination in renal transplant recipients. Nat Clin Pract Nephrol 2008;4:358-9.

188. Carbone J, Sarmiento E, Del Pozo N, et al. Restoration of humoral immunity after IVIG replacement therapy in heart transplant recipients with post-transplant antibody deficiency and severe infections. Clin Transplant 2012;26:E277-83.

189.Lederer DJ, Philip N, Rybak D, et al. Intravenous immunoglobulin for hypogammaglobulinemia after lung transplantation: a randomized crossover trial. PLoS One 2014;9:e103908.

190.Lichvar AB, Ensor CR, Zeevi A, et al. Detrimental Association of hypogammaglobulinemia with chronic lung allograft dysfunction and death is not mitigated by on-demand immunoglobulin G replacement after lung transplantation. Prog Transplant 2018:1526924818817028.

191.Len O, Gavaldà J, Blanes M, et al. A; Spanish Research Network for the Study of Infection in Transplantation. Donor infection and transmission to the recipient of a solid allograft. Am J Transplant 2008;8:2420-5.

192. Mattner F, Kola A, Fischer S, et al. Impact of bacterial and fungal donor organ contamination in lung, heart-lung, heart and liver transplantation. Infection 2008;36:207-12.

193. Wolfe CR, Ison MG; AST Infectious Diseases Community of Practice. Donor-derived infections: Guidelines from the American Society of Transplantation Infectious Diseases Community of Practice. Clin Transplant 2019;33:e13547.

194. Lewis JD, Sifri CD. Multidrug-resistant bacterial donorderived infections in solid organ Transplantation. Curr Infect Dis Rep 2016;18:18.

195. Satlin MJ, Jenkins SG, Walsh TJ. The global challenge of carbapenem-resistant Enterobacteriaceae in transplant recipients and patients with hematologic malignancies. Clin Infect Dis 2014;58:1274-83.

196. Mularoni A, Bertani A, Vizzini G, et al. Outcome of transplantation using organs from donors infected or colonized with carbapenem-resistant Gram-negative bacteria. Am J Transplant 2015;15:2674-82.

197. Morlacchi LC, Greer M, Tudorache I, et al. The burden of sinus disease in cystic fibrosis lung transplant recipients. Transpl Infect Dis 2018;20:e12924.

198.Holzmann D, Speich R, Kaufmann T, et al. Effects of sinus surgery in patients with cystic fibrosis after lung transplantation: a 10-year experience. Transplantation 2004;77:134-6.

199. Leung MK, Rachakonda L, Weill D, et al. Effects of sinus surgery on lung transplantation outcomes in cystic fibrosis. Am J Rhinol 2008;22:192-6.

200. Dorschner P, McElroy LM, Ison MG. Nosocomial infections within the first month of solid organ transplantation. Transpl Infect Dis 2014;16:171-87.

201. Saraswat MK, Magruder JT, Crawford TC, et al. Preoperative Staphylococcus aureus screening and targeted decolonization in cardiac surgery. Ann Thorac Surg 2017;104:1349-56.

202. Clancy CJ, Bartsch SM, Nguyen MH, et al. A computer simulation model of the cost-effectiveness of routine Staphylococcus aureus screening and decolonization among heart and heart-lung transplant recipients. Eur J Clin Microbiol Infect Dis 2014;33:1053-61.

203.Periera MR, Rana MM, on behalf of the AST ID Community of Practice. Methicillin-resistant Staphylococcus aureus in solid organ transplantationGuidelines from the American Society of Transplantation Infectious Diseases Community of Practice. Clin Transplant 2019;33:e13611.

204. Roman A, Bravo C, Levy G, et al. Isoniazid prophylaxis in lung transplantation. J Heart Lung Transplant 2000;19:903-6.

205.Paterson DL, Singh N, Rihs JD, et al. Control of an outbreak of infections due to extended spectrum beta-lactamase-producing Escherichia coli in a liver transplantation unit. Clin Infect Dis 2001;33:126-8.

206. Singh N, Squier C, Wannstedt C, et al. Impact of aggressive infection control strategy on endemic Staphylococcus aureus infection in liver transplant recipients. Infect Control Hosp Epidemiol 2006;27:122-6.

Cite this article as: McCort M, MacKenzie E, Pursell K, Pitrak D. Bacterial infections in lung transplantation. J Thorac Dis 2021;13(11):6654-6672. doi: 10.21037/jtd-2021-12 